\title{
The effects of tolvaptan on patients with severe chronic kidney disease complicated by congestive heart failure
}

\author{
Tomoyuki Otsuka $\cdot$ Yukinao Sakai • \\ Dai Ohno - Tsuneo Murasawa Naoki Sato • \\ Shuichi Tsuruoka
}

Received: 26 December 2012/ Accepted: 21 February 2013/Published online: 13 March 2013

(C) The Author(s) 2013. This article is published with open access at Springerlink.com

\begin{abstract}
Background Tolvaptan, a diuretic with a new mechanism of action, selectively binds to the vasopressin V2 receptor and inhibits reabsorption of water. Its effect on heart failure is proven, but its benefit for patients with chronic kidney disease (CKD) has not been not confirmed. In this study, we examined the effect of tolvaptan on patients with severe CKD.

Methods We analyzed patients with stage 4 or higher CKD who had congestive heart failure that was resistant to existing diuretics. The patients were administered an initial tolvaptan dose of $7.5 \mathrm{mg} /$ day. We assumed urine volume and urine osmolality to be the main effective endpoint and recorded free water clearance, serum osmolality, serum creatinine $(\mathrm{Cr})$ level, and adverse events.

Results There was no instance of clinically significant hypernatremia. The urine volume increased significantly $(P<0.0001)$, as did the urine osmolality $(P=0.0053)$. Free water clearance showed a tendency to increase, although the difference was not statistically significant. The serum creatinine level did not change significantly, and
\end{abstract}

T. Otsuka $\cdot$ Y. Sakai $(\bowtie) \cdot$ D. Ohno $\cdot$ T. Murasawa

Division of Nephrology, Department of Internal Medicine,

Nippon Medical School Musashikosugi Hospital,

1-396 Kosugi-cho, Nakahara-ku, Kawasaki 211-8533, Japan

e-mail: y-sakai@nms.ac.jp

\section{N. Sato}

Division of Cardiology, Department of Internal Medicine, Nippon Medical School Musashikosugi Hospital,

Kawasaki, Japan

S. Tsuruoka

Division of Nephrology, Department of Internal Medicine, Graduate School of Medicine, Nippon Medical School,

Tokyo, Japan there was no clear effect on renal function. However, in patients with stage $5 \mathrm{CKD}$, the serum creatinine level decreased significantly $(n=5, P=0.0435)$. There were no adverse events.

Conclusion We confirmed that tolvaptan has a diuretic effect in patients with both severe CKD and congestive heart failure without causing either clinically significant hypernatremia or an adverse effect on renal function. Tolvaptan is an effective diuretic for patients with CKD.

Keywords Tolvaptan - Chronic kidney disease . Diuretic $\cdot$ Congestive heart failure $\cdot$ Renoprotection

\section{Introduction}

Tolvaptan binds selectively to the V2 receptor ( 1 of the 3 vasopressin receptors: V1a, V1b, and V2), disturbs the movement of aquaporin 2 into the luminal side of cortical collecting duct cells through activation of cAMP, and inhibits reabsorption of water. It thus uses a new mechanism of action for producing water diuresis $[1,2]$. The effect of tolvaptan is expected to be unlike that of conventional diuretics [3], and its short-term effects for treating heart failure have been investigated in the ACTIVE in CHF [4] and EVEREST [5, 6] studies. However, careful administration has been suggested, because volume depletion by diuresis leads to a decrease in renal blood flow in patients with serious renal dysfunction; thus, renal function may worsen [7]. However, one study has suggested that the renal blood flow and glomerular filtration rate (GFR) are not reduced by tolvaptan [8]. In addition, the protective function of the kidney is expected to initiate a diuretic effect without activating the renin-angiotensin system $[9,10]$. There are many unanswered questions 
about the effect of tolvaptan on renal function, and there are few reports of its use for patients with severe renal dysfunction [11]. In this report, we examined the effect of tolvaptan in patients with severe chronic kidney disease (CKD) complicated by congestive heart failure who were resistant to existing diuretics.

\section{Subjects and methods}

This report is a retrospective observational study of usual practice, and there was no planned protocol. However, we explained the likelihood of side effects of tolvaptan, which was a new medicine, to all patients and obtained their consent. We included patients with stage 4 CKD or higher and congestive heart failure who were admitted to our hospital. The initial tolvaptan dose was $7.5 \mathrm{mg} /$ day. After 2

Table 1 Patient baseline characteristics $(N=8)$

\begin{tabular}{lc}
\hline Parameter & Statistics \\
\hline Blood pressure (mmHg) & \\
Systolic & $155.3 \pm 24.8$ \\
Diastolic & $88.8 \pm 17.9$ \\
NYHA II:III, $n$ & $5: 3$ \\
HANP $(\mathrm{pg} / \mathrm{ml})$ & $255.6 \pm 236.5$ \\
BNP $(\mathrm{pg} / \mathrm{ml})$ & $1012 \pm 1356$ \\
sCr $(\mathrm{mg} / \mathrm{dl})$ & $7.57 \pm 5.66$ \\
sCr stage 5 (mg/dl) & $10.08 \pm 5.91$ \\
Na $(\mathrm{mEq} / \mathrm{l})$ & $138.0 \pm 6.3$ \\
UV $(\mathrm{ml} / \mathrm{day})$ & $1263 \pm 655$ \\
uOsm $(\mathrm{mOsm} / \mathrm{kg})$ & $275.0 \pm 39.8$ \\
sOsm $(\mathrm{mOsm} / \mathrm{kg})$ & $296.5 \pm 7.6$ \\
\hline
\end{tabular}

$B N P$ B-type natriuretic peptide, HANP human atrial natriuretic peptide, NYHA New York Heart Association, $u O s m$ urine osmolality, sOsm serum osmolality, $U V$ urine volume or 3 days, the dose was increased to $15 \mathrm{mg} /$ day depending on the observed efficacy and adverse events. The treatmenttargeted value for serum $\mathrm{Na}$ concentration controls was set at $144 \mathrm{mEq} / \mathrm{l}$. If the serum $\mathrm{Na}$ concentration increased to $\geq 145 \mathrm{mEq} / \mathrm{l}$, we reduced the tolvaptan dose. Urine volume and urine osmolality were assumed to be the main effective endpoint. We evaluated free water clearance, serum osmolality, serum creatinine $(\mathrm{Cr})$ level, and adverse events. In addition, we compared values of human atrial natriuretic peptide (HANP) and B-type natriuretic peptide (BNP) before the administration of tolvaptan and 1 month later.

The value of each measurement is expressed as mean \pm standard deviation (SD). We conducted one-way analysis of variance (ANOVA) by considering data multiplicity over time and used Tukey's multiple comparison test for the subsequent post hoc test. We used the paired $t$ test for comparisons of HANP and BNP values. We considered $P<0.05$ as statistically significant. In addition, for each set of data, a regression line was obtained.

\section{Results}

Tables 1 and 2 show a summary of the patients' backgrounds. The study group consisted of 5 men and 3 women with a mean age of $53.7 \pm 7.7$ years and a mean serum $\mathrm{Cr}$ level of $7.57 \pm 5.66 \mathrm{mg} / \mathrm{dl}$ at admission. Their cardiac function grade was assessed according to the New York Heart Association (NYHA) criteria. Five patients were class II and 3 patients were class III. Primary diseases included rapidly progressive glomerulonephritis $(n=1)$, methicillin-resistant Staphylococcus aureus-associated nephritis $(n=1)$, benign nephrosclerosis $(n=1)$, polycystic kidney disease $(n=3)$, and diabetic nephropathy $(n=2)$. Patients were using the following diuretics: azosemide $(60 \mathrm{mg} / \mathrm{day} ; \quad n=1)$, eplerenone $(50 \mathrm{mg} / \mathrm{day}$; $n=1)$, torasemide $(8 \mathrm{mg} / \mathrm{day} ; n=2)$, and furosemide

Table 2 Patient baseline profile $(N=8)$

\begin{tabular}{|c|c|c|c|c|c|c|c|c|c|c|c|}
\hline No. & Age & Gender & $\begin{array}{l}\text { Primary } \\
\text { diseases }\end{array}$ & $\begin{array}{l}\text { CKD } \\
\text { stage }\end{array}$ & NYHA & $\begin{array}{l}\text { Tolvaptan } \\
\text { (mg) }\end{array}$ & $\begin{array}{l}\text { Furosemide } \\
(\mathrm{mg})\end{array}$ & $\begin{array}{l}\text { Torasemide } \\
(\mathrm{mg})\end{array}$ & $\begin{array}{l}\text { Azosemide } \\
(\mathrm{mg})\end{array}$ & $\begin{array}{l}\text { Eplerenon } \\
\text { (mg) }\end{array}$ & $\begin{array}{l}\text { Olmesartan } \\
(\mathrm{mg})\end{array}$ \\
\hline 1 & 56 & M & Nephrosclerosis & 5 & III & 15 & 180 & & & & 40 \\
\hline 2 & 64 & $\mathrm{~F}$ & PKD & 5 & II & 15 & 200 & & & & 40 \\
\hline 3 & 50 & M & MRSA nephritis & 5 & III & 7.5 & 120 & & 60 & & 40 \\
\hline 4 & 49 & M & PKD & 5 & II & 7.5 & & 8 & & & 40 \\
\hline 5 & 65 & $\mathrm{~F}$ & PKD & 5 & II & 7.5 & 140 & & & 50 & \\
\hline 6 & 51 & $\mathrm{~F}$ & RPGN & 4 & II & 15 & & 8 & & & 40 \\
\hline 7 & 53 & M & DN & 4 & II & 15 & 180 & & & & 40 \\
\hline 8 & 42 & M & $\mathrm{DN}$ & 4 & III & 15 & 40 & & & & 40 \\
\hline
\end{tabular}

CKD chronic kidney disease, DN diabetic nephropathy, NYHA New York Heart Association, MRSA nephritis methicillin-resistant Staphylococcus aureus-associated nephritis, $P K D$ polycystic kidney disease 
Fig. 1 Overall changes in $24 \mathrm{~h}$ urine volume (a) and each change in each patient (b). *Significant according to the results of a one-way ANOVA $(P<0.0001)$ and Tukey's multiple comparison testing (0 vs. 1,0 vs. 2,0 vs. 3,0 vs. 4,0 vs. 5,0 vs. 6 ) a

$\mathrm{mL}$

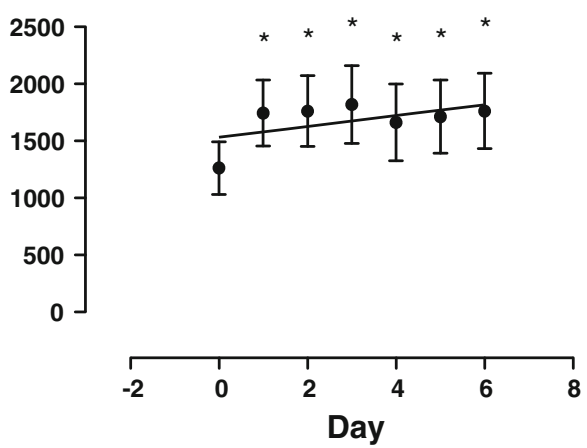

a

mOsm/kg

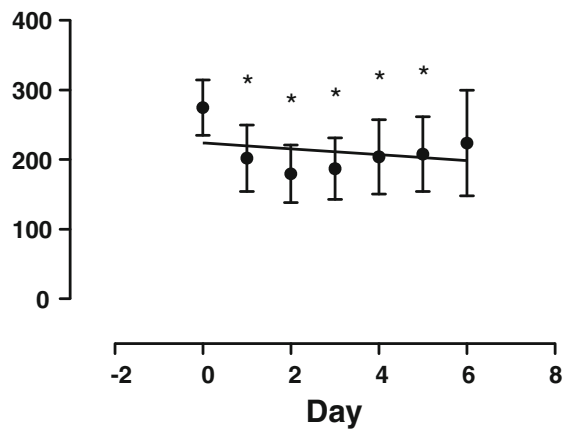

b

$\mathrm{mL}$

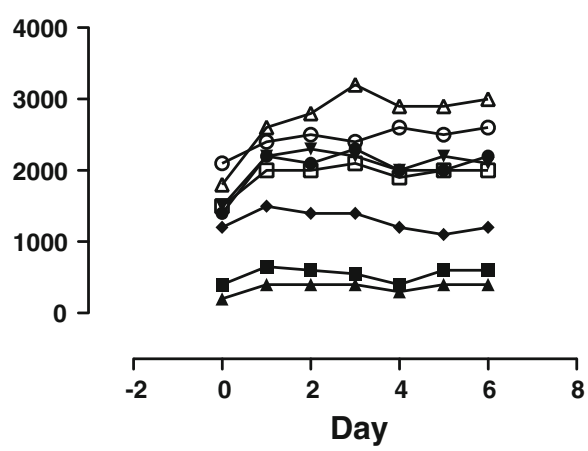

b

mOsm/kg
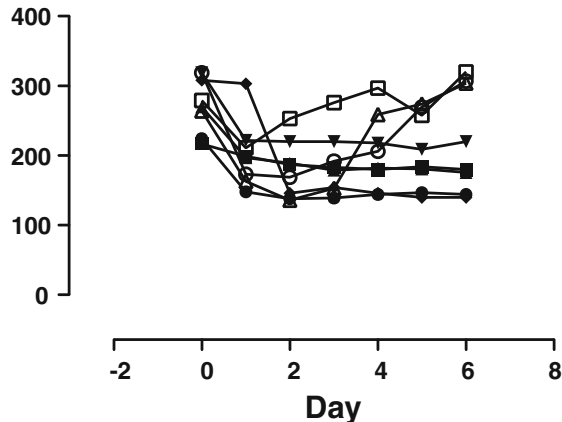

osmolality (a) and each change in each patient (b). *Significant according to the results of a oneway ANOVA $(P=0.0010)$ and Tukey's multiple comparison testing ( 0 vs. 1,0 vs. 2,0 vs. 3,0 vs. 4,0 vs. 5 )

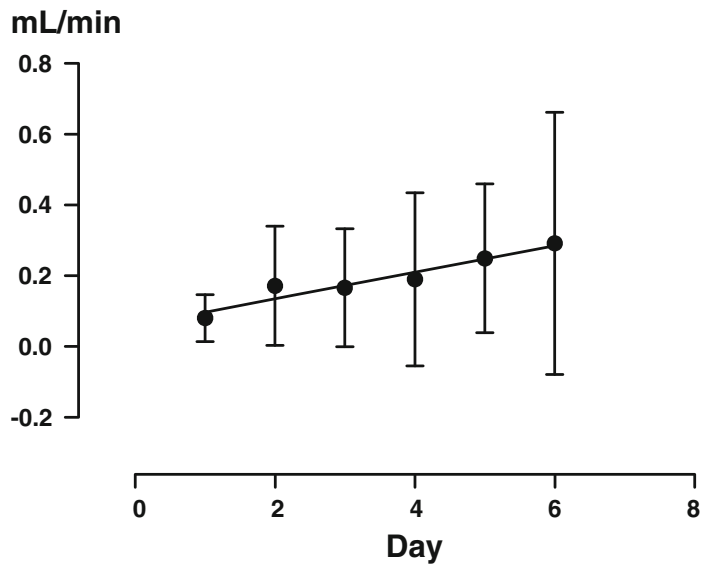

Fig. 3 Changes in free water clearance

(40-200 mg/day; $n=6$ ). The renin-angiotensin-aldosterone system (RAAS) inhibitor (olmesartan) was prescribed for 7 patients at a dose of $40 \mathrm{mg}$. Eplerenone $(50 \mathrm{mg}$ ) was prescribed for the remaining 1 patient. No patient took digitalis.

The dose of tolvaptan remained constant after the 3rd day, with 5 patients receiving $15 \mathrm{mg} /$ day and 3 receiving $7.5 \mathrm{mg} /$ day. During the course of the study, 1 patient's $\mathrm{Na}$
$\mathrm{mEq} / \mathrm{L}$

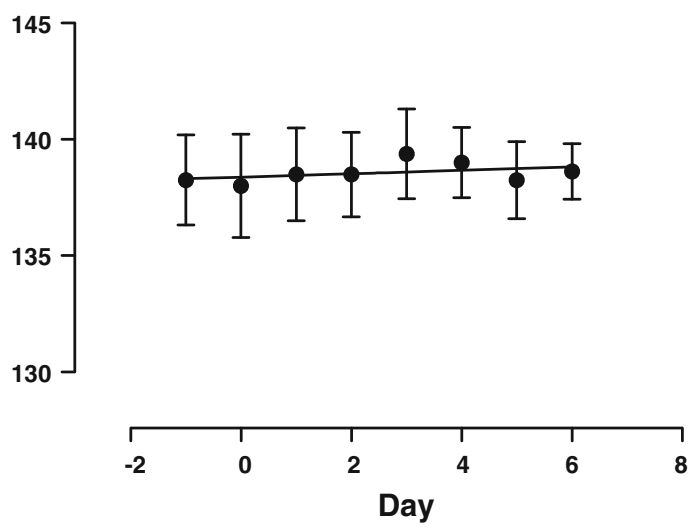

Fig. 4 Changes in serum $\mathrm{Na}$ concentration

concentration exceeded $145 \mathrm{mEq} / \mathrm{l}$; however, this did not continue for more than $24 \mathrm{~h}$ and eventually decreased to $<144 \mathrm{mEq} / \mathrm{l}$. Therefore, we did not reduce the tolvaptan dose.

Urine volume increased (Fig. 1), with a significant difference from the next day $(P<0.0001)$, and the urine osmolality decreased similarly (Fig. 2) $(P=0.0010)$. Free water clearance showed a tendency to increase, but the 
Fig. 5 Overall changes in serum $\mathrm{Cr}$ level (a) and in stage 5 CKD patients alone (b). *Significant according to the results of a one-way ANOVA $(P<0.0435)$ and Tukey's multiple comparison testing (0 vs. 6) a

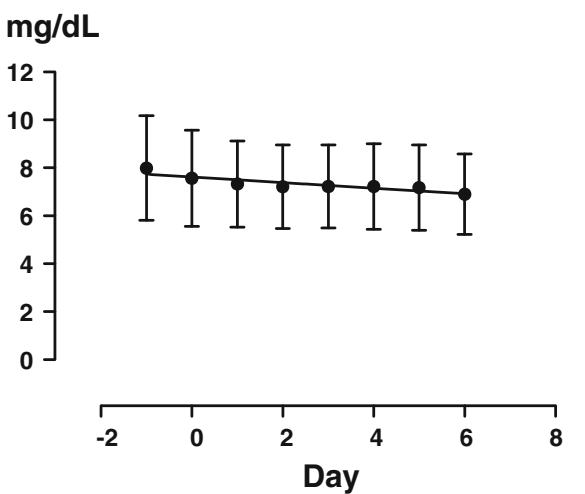

a natriuretic peptide (HANP) (a) and B-type natriuretic peptide (BNP) (b). $P$ values are compared with baseline using the paired $t$ test

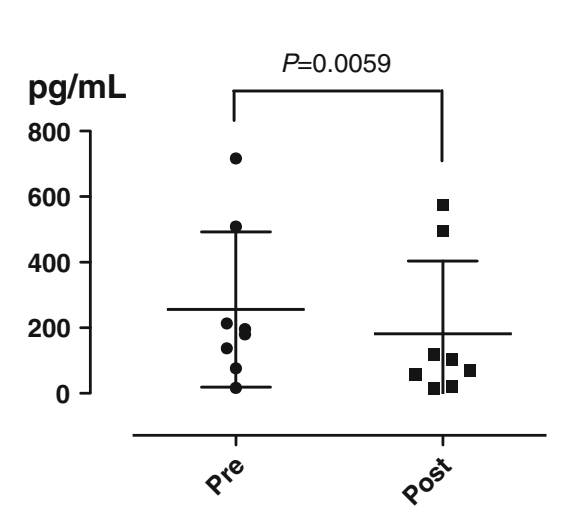

b

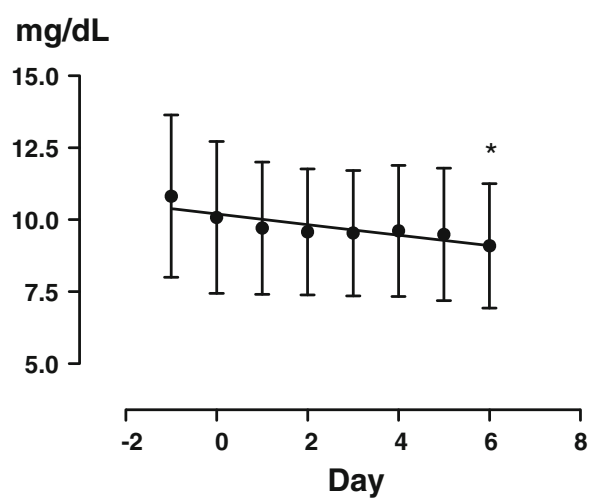

b

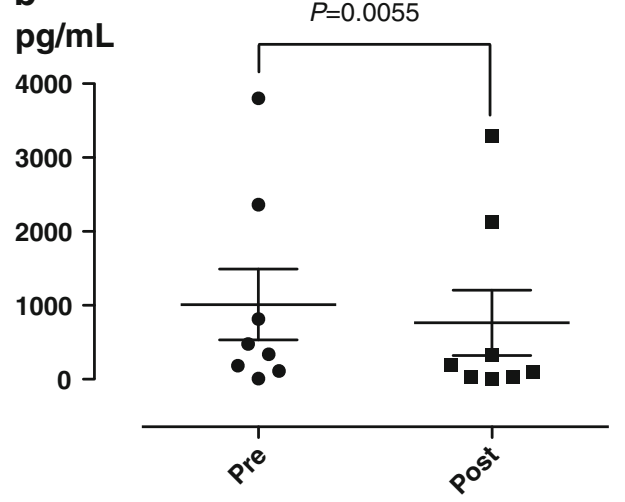

difference was not significant (Fig. 3). The serum osmolality showed almost no change, as was the case for the serum $\mathrm{Na}$ concentration (Fig. 4).

The serum Cr level did not show a significant change, and there was little effect on renal function (Fig. 5a). However, the serum creatinine level significantly decreased when it was analyzed for patients with CKD stage 5 alone (Fig. 5b) $(n=5, P=0.0435)$.

HANP and BNP decreased significantly (Fig. 6) ( $P=0.0059$ and 0.0055 , respectively). However, blood pressure showed a tendency toward decreasing, but the difference was not significant (data not shown).

\section{Discussion}

In this study, we showed that tolvaptan produced a consistent diuretic effect among patients with severe CKD and congestive heart failure. If the kidney has some residual renal function, tolvaptan, which is a water diuretic that significantly decreases urine osmolality, enables maintenance of the osmoregulation of the body fluids by the renal cortical collecting tubules. However, clinically significant hypernatremia did not occur, probably because we used a natriuretic in combination with tolvaptan. In addition, in accordance with alleviation of congestion by tolvaptan, the effect of furosemide may also be improved. This may be one of the reasons why the urine osmolality and urine volume did not change in parallel.

A study reported increased renal blood flow after administration of tolvaptan among patients with heart failure, but this finding was not observed among patients with renal failure [8]. The mechanism underlying this effect is not yet understood. One of the reasons for the improvement in the serum $\mathrm{Cr}$ level in CKD stage 5 patients may be increased renal blood flow with tolvaptan. Further, the serum $\mathrm{Cr}$ level may have decreased because "congestive kidney failure" [12] was ameliorated by tolvaptan's diuretic effect. We acknowledge the likelihood that an increase in renal blood flow may be caused by the diuretic effect of tolvaptan in cases in which the effect was not obtained from diuretics such as furosemide [13]. The effect and mechanism of action of tolvaptan in the maintenance of renal function need to be elucidated.

Vasopressin concentrations were not measured in this study, but it is assumed that they were high [14]. Further, although our patients were in a state of renal failure, it is inferred that some had collecting tubules that were 
responsive to vasopressin. If this collecting tubule function was measured and evaluated initially, it would have been possible to ascertain whether tolvaptan is effective in disorders such as heart failure with advanced renal failure.

In summary, we examined the additive effect of tolvaptan among patients using other diuretics for severe CKD complicated by congestive heart failure. Urine volume and urine osmolality changed significantly, free water clearance showed a tendency to increase, and tolvaptan showed a consistent effect. Hypernatremia did not occur. There was no exacerbation of the serum $\mathrm{Cr}$ level and no adverse effect on renal function. We showed a decrease in the serum $\mathrm{Cr}$ level in patients with stage 5 CKD. Tolvaptan is an optional effective diuretic for patients with CKD.

\section{Conflict of interest None.}

Open Access This article is distributed under the terms of the Creative Commons Attribution License which permits any use, distribution, and reproduction in any medium, provided the original author(s) and the source are credited.

\section{References}

1. Yamamura Y, Nakamura S, Itoh S, et al. OPC-41061, a highly potent human vasopressin V2-receptor antagonist: pharmacological profile and aquaretic effect by single and multiple oral dosing in rats. J Pharmacol Exp Ther. 1998;287:860-7. http:// www.ncbi.nlm.nih.gov/pubmed/9864265.

2. Hirano T, Yamamura Y, Nakamura S, Onogawa T, Mori T. Effects of the $\mathrm{V}(2)$-receptor antagonist OPC-41061 and the loop diuretic furosemide alone and in combination in rats. J Pharmacol Exp Ther. 2000;292:288-94. http://www.ncbi.nlm.nih.gov/pubmed/10604960.

3. Gheorghiade M, Niazi I, Ouyang J, et al. Vasopressin V2-receptor blockade with tolvaptan in patients with chronic heart failure: results from a double-blind, randomized trial. Circulation. 2003;107: 2690-6. http://www.ncbi.nlm.nih.gov/pubmed/12742979.

4. Gheorghiade M, Gattis WA, O'Connor CM, et al. Effects of tolvaptan, a vasopressin antagonist, in patients hospitalized with worsening heart failure. JAMA. 2004;291:1963-71.
5. Gheorghiade M, Orlandi C, Burnett JC, et al. Rationale and design of the multicenter, randomized, double-blind, placebocontrolled study to Evaluate the Efficacy of Vasopressin Antagonism in Heart Failure: Outcome Study with Tolvaptan (EVEREST). J Card Fail. 2005;11:260-9.

6. Blair JEA, Pang PS, Schrier RW, et al. Changes in renal function during hospitalization and soon after discharge in patients admitted for worsening heart failure in the placebo group of the EVEREST trial. Eur Heart J. 2011;32:2563-72.

7. Vaduganathan M, Gheorghiade M, Pang PS, et al. Efficacy of oral tolvaptan in acute heart failure patients with hypotension and renal impairment. J Cardiovasc Med (Hagerstown). 2012;13:415-22. http://www.ncbi.nlm.nih.gov/pubmed/22673023.

8. Costello-Boerrigter LC, Smith WB, Boerrigter G, Ouyang J, Zimmer CA, Orlandi C, Burnett JC Jr. Vasopressin-2-receptor antagonism augments water excretion without changes in renal hemodynamics or sodium and potassium excretion in human heart failure. Am J Physiol Renal Physiol. 2006;290:F273-8.

9. Okada T, Sakaguchi T, Hatamura I, et al. Tolvaptan, a selective oral vasopressin V2 receptor antagonist, ameliorates podocyte injury in puromycin aminonucleoside nephrotic rats. Clin Exp Nephrol. 2009;13:438-46. http://www.ncbi.nlm.nih.gov/pubmed/ 19452240.

10. Onogawa T, Sakamoto Y, Nakamura S, Nakayama S, Fujiki H, Yamamura Y. Effects of tolvaptan on systemic and renal hemodynamic function in dogs with congestive heart failure. Cardiovasc Drugs Ther. 2011;25 Suppl 1:S67-76. http://www.ncbi.nlm. nih.gov/pubmed/22120095.

11. Matsue Y, Suzuki M, Seya M, et al. Tolvaptan reduces the risk of worsening renal function in patients with acute decompensated heart failure in high-risk population. J Cardiol. 2012. http://www. ncbi.nlm.nih.gov/pubmed/23159210.

12. Mullens W, Abrahams Z, Francis GS, et al. Importance of venous congestion for worsening of renal function in advanced decompensated heart failure. J Am Coll Cardiol. 2009;53:589-96. http://www.ncbi.nlm.nih.gov/pubmed/19215833.

13. Peacock WF, Costanzo MR, De Marco T, et al. Impact of intravenous loop diuretics on outcomes of patients hospitalized with acute decompensated heart failure: insights from the ADHERE registry. Cardiology. 2009;113:12-9. http://www.ncbi. nlm.nih.gov/pubmed/18931492.

14. Bankir L, Bouby N. Vasopressin and urinary concentration: additional risk factors in the progression of chronic renal failure. Am J Kidney Dis. 1991;17:20-6. http://www.ncbi.nlm.nih.gov/ pubmed/2024668. 